\title{
"Apasionado por ese movimiento científico": Cornelio Moyano Gacitúa y el estudio empírico de la delincuencia argentina a comienzos del siglo XX
}

"Passionate about that Scientific Movement": Cornelio Moyano Gacitúa and the Empirical Study of Argentine Crime in early 20th century

"Passionné par ce mouvement scientifique": Cornelio Moyano Gacitúa et l'étude empirique de la délinquance argentine au début du XXe siècle

\section{María Belén Portelli}

\section{(2) OpenEdition}

\section{Journals}

Edición electrónica

URL: http://journals.openedition.org/rhj/909

DOI: $10.4000 /$ rhj.909

ISSN: 0719-4153

Editor

ACTO Editores Ltda

Referencia electrónica

María Belén Portelli, «"Apasionado por ese movimiento científico": Cornelio Moyano Gacitúa y el

estudio empírico de la delincuencia argentina a comienzos del siglo XX », Revista Historia y Justicia [En línea], 8 | 2017, Publicado el 30 mayo 2017, consultado el 02 mayo 2019. URL : http:// journals.openedition.org/rhj/909; DOI : 10.4000/rhj.909 


\title{
"APASIONADO POR ESE MOVIMIENTO CIENTÍFICO": CORNELIO MOYANO GACITÚA Y EL ESTUDIO EMPÍRICO DE LA DELINCUENCIA ARGENTINA A COMIENZOS DEL SIGLO XX
}

\author{
María Belén PORTELLI $(*)$
}

En línea con las producciones historiográficas recientes, el presente artículo procura contribuir al conocimiento de un diverso grupo de intelectuales que adhirieron a la criminología positivista en la Argentina de finales del siglo XIX y comienzos del XX. Para ello, se analiza la obra de Comelio Moyano Gacitúa, un jurista cordobés que alcanzó una distinguida proyección nacional en el campo criminológico. En particular, se trata de dilucidar cuál fue el impacto metodológico que la criminología tuvo en sus investigaciones y qué operaciones científicas desarrolló para el estudio de la delincuencia en la Argentina.

Palabras Clave: delincuencia, criminología positivista, estadísticas criminales, Argentina, comienzos del siglo XX

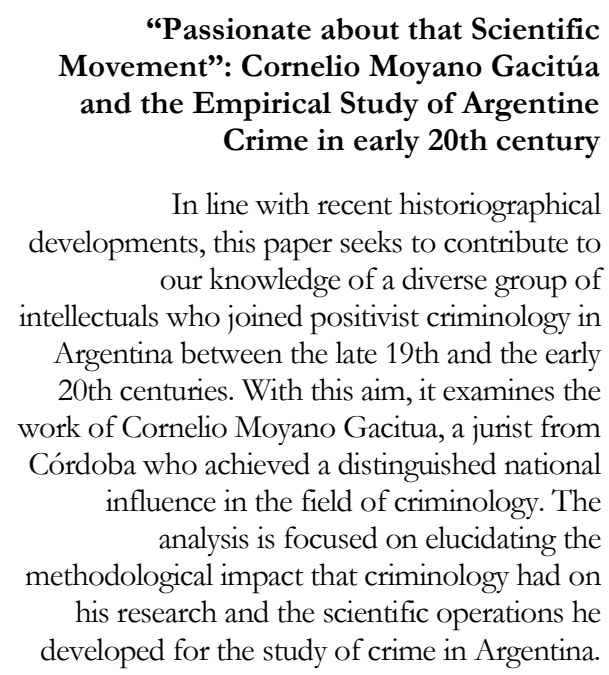

Keywords: Crime, positivist criminology, criminal statistics, Argentina, early 20th century

\begin{abstract}
"Passionné par ce mouvement scientifique": Cornelio Moyano Gacitúa et l'étude empirique de la délinquance argentine au début du XXe siècle

En accord avec les productions historiographiques récentes, cet article vise à contribuer à la connaissance d'un groupe varié d'intellectuels qui ont adhéré à la criminologie positiviste en Argentine, au tournant du XXe siècle. Nous analysons l'œuvre de Cornelio Moyano Gacitúa, un juriste de Córdoba qui obtint une reconnaissance nationale distinguée dans le champ des études criminologiques. Il s'agit en particulier d'expliciter quel fut l'impact méthodologique que la criminologie a eu dans ses recherches et quelles furent les opérations scientifiques développées pour l'étude de la délinquance en Argentine.
\end{abstract}

Mots clé: délinquance, criminologie positiviste, statistiques criminelles, Argentine, XXe siècle

Recibido: 23 de diciembre de 2016 / Aceptado: 4 de abril de 2017

$\left(^{*}\right)$ Becaria Posdoctoral del Consejo Nacional de Investigaciones Científicas y Técnicas, CONICET. Investigadora del Centro de Estudios Históricos "Prof. Carlos S. A. Segreti”. Profesora asistente de la Facultad de Filosofía y Humanidades, Universidad Nacional de Córdoba. Profesora titular de la Facultad de Filosofía y Humanidades, Universidad Católica de Córdoba. Córdoba, Argentina. belenportelli@gmail.com 


\title{
"Apasionado por ese movimiento científico": Cornelio Moyano Gacitúa y el estudio empírico de la delincuencia argentina a comienzos del siglo XX
}

\author{
María Belén PORTELLI
}

\section{Introducción}

A comienzos de la década del 80', en uno de los primeros esfuerzos por construir una historia de la criminología en América Latina, Rosa del Olmo destacó la rápida acogida y el fuerte interés que la disciplina europea encontró en la Argentina finisecular ${ }^{1}$. Para explicar este fenómeno, indicó que las doctrinas criminológicas respondían a las necesidades de las clases dominantes de enfrentar el problema del delito, ofreciendo una "base científica" que sirvió como instrumento de legitimación de una política de control social. Según su análisis, el pensamiento de los criminólogos positivistas fue una herramienta central para identificar, segregar o disciplinar a aquellos sectores resistentes al orden, y se le consideraba necesario para asegurar la inserción del país en la economía capitalista mundial ${ }^{2}$.

En sintonía con esta línea interpretativa, diversas producciones historiográficas desarrolladas en la Argentina en los años ' 90 destacaron que la criminología positivista ofreció una serie de instrumentos represivos y normalizadores, útiles para enfrentar los desafíos inaugurados por el proceso de modernización experimentado por el país entre fines del siglo XIX y comienzos del XX. Beatriz Ruibal señaló que el discurso criminológico no se acotó al problema de la delincuencia, sino que también abarcó un amplio abanico de acciones que se reputaban peligrosas para la estabilidad social. Éstas incluían desde las actividades que conformaban la "mala vida" -el alcohol, el juego, la prostitución, el vagabundeo y la mendicidad, entre otras - hasta la superposición de la criminalidad con la protesta obrera y el anarquismo. Ante la necesidad de regular y combatir aquellos comportamientos que atentaran contra el nuevo orden económico y social, las ideas de los criminólogos

\footnotetext{
${ }_{1}$ El artículo presenta algunos resultados de la tesis de Doctorado en Historia, titulada "Los intelectuales, la cuestión social y la construcción de políticas sociales durante el período de Modernización. Córdoba, 18901936", inscripta en la Universidad Nacional de Córdoba y defendida y aprobada en marzo de 2016. El proyecto de dicha investigación contó con el financiamiento de las becas internas de postgrado tipos I y II del CONICET (2010-2015).

2 Del Olmo, Rosa, América Latina y su criminología, Siglo XXI, México D. F., 1984, p. 136.
} 


\section{Revista Historia y Justicia}

ISSN 0719-4153 revista.historiayjusticia.org

N8 - Santiago de Chile, abril 2017, p. 166-194

contribuyeron a establecer "dispositivos de saber-poder" destinados a la extensión del control social -en la policía, en la penitenciaría y en las instituciones de menores ${ }^{3}$. Por medio de estos mecanismos se buscaba garantizar tanto la ubicación de los individuos productores en el sistema, como la separación, dentro del mismo, de aquellos considerados no aptos o perturbadores del desarrollo.

Otro aporte fue realizado por Ricardo Salvatore, quien reconstruyó las reformas que los criminólogos introdujeron en el sistema penitenciario entre 1900 y 1920 . De acuerdo al autor, estas modificaciones tendieron a inculcar una disciplina laboral entre los reclusos, con el fin de desarrollar la fuerza productiva de amplios sectores "desgranados" del mercado de trabajo -vagabundos, desocupados, asalariados ocasionales ${ }^{4}$. Asimismo, Eduardo Zimmermann analizó la influencia de la doctrina criminológica $-\mathrm{y}$, especialmente, su concepto de defensa social- en las medidas de represión del anarquismo implementadas por el Estado nacional, particularmente en las leyes de expulsión de extranjeros sancionadas en 1902 y 19105. Con posterioridad, y profundizando esta perspectiva, Salvatore postuló que la criminología positivista creó una "nueva cultura estatal" en la Argentina del giro de siglo. Sus cultivadores ocuparon posiciones dentro de las instituciones de control social, al tiempo que brindaron a las elites dirigentes los principios y los argumentos que necesitaban para conservar el orden y asegurar la gobernabilidad ${ }^{6}$.

En los últimos años se elaboraron nuevos estudios que, sin negar que la criminología permitió la confluencia de la ciencia con los instrumentos de control social, restituyeron otras dimensiones del fenómeno y lograron matizar o complejizar las premisas más tradicionales. Por un lado, se exploraron los alcances concretos de los postulados criminológicos. Estos análisis revelaron que, a pesar de la rápida expansión del predicamento de los criminólogos en distintos ámbitos políticos e intelectuales, ello no se tradujo en una total ni automática transformación institucional según los principios proclamados por la ciencia. Así, por ejemplo, el trabajo de Lila Caimari contrastó la relación entre los saberes criminológicos y la realidad de las instituciones penales, revelando "el abismo que separaba a las ideas científicojurídicas de las prácticas punitivas"7. Esto contribuyó a exponer las limitaciones, las dificultades, las resistencias y las distorsiones que las agendas de los criminólogos encontraron en el plano de la realidad.

\footnotetext{
${ }^{3}$ Ruibal, Beatriz Celina, Ideología del control social. Buenos Aires 1880-1920, CEAL, Buenos Aires, 1993, p. 14.

${ }^{4}$ Salvatore, Ricardo, "Criminology, prison reform and the Buenos Aires working class", Journal of Interdisciplinary History, Cambridge, vol. 23, n², 1992, p. 279-299.

5 Zimmermann, Eduardo, Los liberales reformistas. La cuestión social en la Argentina 1890-1916, Editorial Sudamericana, Buenos Aires, 1995, p. 126-172.

'Salvatore, Ricardo, "Sobre el surgimiento del estado médico-legal en la Argentina (1890-1940)", Estudios Sociales, Santa Fe, n²0, 2001, p. 81-114.

${ }^{7}$ Caimari, Lila, Apenas un delincuente: crimen, castigo y cultura en la Argentina, 1880-1955, Siglo XXI, Buenos Aires, 2004, p. 17.
} 
Otras producciones se concentraron en los procesos de recepción y apropiación del pensamiento criminológico en la Argentina finisecular ${ }^{8}$. Estas lecturas atendieron, por un lado, a las particularidades del contexto nacional y, por otro, a una densa trama de actores, redes sociales, instituciones, tradiciones intelectuales, lecturas y debates. Esto permitió concluir que el proceso de recepción de las ideas criminológicas en el país distó de ser una mera transposición pasiva o una simple traducción lineal o literal de los desarrollos europeos. Los científicos argentinos desarrollaron lecturas selectivas, distanciamientos críticos e interpretaciones creativas que otorgaron nuevos sentidos a las teorías importadas. En consecuencia, el pensamiento criminológico no compuso un cuadro uniforme sino un conjunto diverso y heterogéneo.

La renovación también se puso de manifiesto en el examen del valor científico de los estudios criminológicos, en una relectura que tendió a resaltar su trabajo etnográfico y el interés por producir evidencias empíricas ${ }^{9}$. En su reciente análisis de la obra de Eusebio Gómez, Ricardo Salvatore señaló que los estudios fundacionales de la criminología estuvieron cargados de condenas morales, prejuicios raciales y propósitos disciplinantes, pero en ellos también se hicieron presentes procedimientos y métodos de validación de la ciencia de la sociedad, tal como era entendida a principios del siglo XX. Aunque modeladas por categorías conceptuales, esquemas cognoscitivos y concepciones subjetivas previas, las primeras obras de criminología estuvieron imbuidas de un impulso empirista que los condujo a realizar estudios experimentales ${ }^{10}$.

Una de las estrategias para captar estos matices consiste en operar a escala individual. Focalizar la mirada en un conjunto de figuras intelectuales ligadas a la criminología permite reconstruir sus trayectorias, sus ideas, sus metodologías y sus prácticas, y así componer un retrato más plural y complejo del pensamiento criminológico en la Argentina.

En diálogo con estas nuevas líneas de indagación, el presente artículo procura contribuir al conocimiento de los intelectuales argentinos adherentes a la criminología positivista entre finales del siglo XIX y comienzos del XX. Se analiza en particular la obra de Cornelio Moyano Gacitúa (1858-1911), un jurista cordobés que alcanzó una distinguida proyección nacional en el ejercicio de la magistratura y en la producción académica circunscrita al terreno

\footnotetext{
8 Sozzo, Máximo, “'Traduttore traditore'. Traducción, importación cultural e historia del presente de la criminología en América Latina", Cuadernos de Doctrina y Jurisprudencia Penal, Buenos Aires, vol. 7, n¹3, 2001, p. 353-431; Melossi, Darío \& Sozzo, Máximo \& Richard Sparks (eds.), Travels of the Criminal Question. Cultural Embeddedness and Diffusion, Hart Publishing, Oxford, 2011; Cesano, José Daniel, Élites, redes intelectuales y recepción en la cultura jurídico penal de Córdoba: 1900-1950, Ediciones del Copista, Córdoba, 2011.

9 Galeano, Diego, "Civilización y delito. Notas sobre cuatro criminólogos argentinos", Revista de Historia del Derecho, Buenos Aires, núm. 45, 2013, p. 265-277.

10 Salvatore, Ricardo, "Usos científicos de La mala vida de Eusebio Gómez" en Salvatore, Ricardo \& Osvaldo Barreneche (eds.), El delito y el orden en perspectiva histórica, Prohistoria, Rosario, 2013, p. 99-120.
} 
del derecho penal. En general, su trabajo fue analizado por quienes intentaron establecer su filiación teórica o sus ideas en torno a la relación entre delito e inmigración. Sin embargo, numerosos aspectos de su pensamiento y su trayectoria aún precisan ser explorados con mayor profundidad.

El presente artículo pretende dilucidar cuál fue el impacto metodológico que la criminología tuvo en sus investigaciones y qué operaciones científicas desarrolló para el estudio de la delincuencia en la Argentina. Para ello se examinarán los principios y procedimientos que guiaron su labor en materia de observación, búsqueda de evidencias y formulación de hipótesis.

El postulado central que propone el trabajo indica que Moyano Gacitúa incorporó el método experimental de la escuela positivista, haciendo suyo el principio de que los factores causales del delito debían estudiarse a la luz de la observación y no a partir de meras generalizaciones metafísicas. Esto se plasmó muy claramente en La delincuencia argentina (1905), una obra de gran contenido empírico, donde apeló a la cuantificación para reconstruir las dimensiones y las características que el problema asumía en el suelo nacional. A partir del análisis de las evidencias cuantitativas, el jurista cordobés pudo revisar algunas nociones preconcebidas y elaborar nuevas conclusiones sobre el fenómeno delictivo. Así pues, los aportes metodológicos de la criminología le permitieron construir nuevos conocimientos sobre una realidad social en acelerada transformación.

\section{El problema de la delincuencia y los inicios de la criminología en la Argentina moderna}

Entre finales del siglo XIX y principios del XX la Argentina se incorporó al mercado internacional como un país exportador de productos primarios. Este proceso fue alentado por las inversiones externas, la incorporación de extensos territorios para la producción, la difusión de nuevos medios de transporte y la masiva llegada de inmigrantes europeos que aportaron su mano de obra. Como resultado, se produjo un vertiginoso crecimiento económico, que alcanzó un promedio anual del 6\% entre 1880 y 191411. Por su parte, el fenómeno inmigratorio impulsó un rápido aumento demográfico, pues la población pasó de 1.8 millones de habitantes en 1869 a 7.9 millones en 1914.

Esta expansión se observó especialmente en la región Litoral, de fértiles llanuras cercanas a los puertos, que concentró más del 70\% del total poblacional. La inmigración también impactó la composición de la población: si en 1895 cerca de un $25 \%$ de los habitantes del país era extranjero, hacia 1914 ese porcentaje se elevó a casi al 33\% (un tercio). A la vez, la tasa de población urbana se elevó notablemente, alcanzando el 57.3\% en 1914. El proceso de

${ }^{11}$ Cortés Conde, Roberto, La economía politica de la Argentina en el siglo XX, Edhasa, Buenos Aires, 2005, p. 18. 
urbanización se desarrolló de manera más intensa en las ciudades de Buenos Aires, Rosario y Córdoba, que experimentaron un crecimiento demográfico explosivo ${ }^{12}$.

La sociedad que emergió de estas transformaciones albergó profundas desigualdades, tensiones y conflictos que hicieron visibles los límites o los efectos menos deseados de la modernización. La emergencia de la denominada "cuestión social" fue, tal vez, una de sus principales contradicciones. El término definía a un vasto conjunto de desajustes derivados de la explosión demográfica y el crecimiento urbano, tales como el hacinamiento habitacional, la propagación de enfermedades y epidemias, el aumento de la pobreza y los problemas relacionados con el mundo del trabajo ${ }^{13}$.

El incremento de la delincuencia fue otra de las manifestaciones de la cuestión social. Las ciudades se convirtieron en nuevos escenarios de la criminalidad. En la ciudad de Buenos Aires, las estadísticas policiales registraron un altísimo aumento de los delitos contra las personas de 629 a 3.166 casos entre 1885 y $1914^{14}$. Entre éstos, predominaron los hechos de violencia (lesiones y homicidios por imprudencia) desarrollados generalmente en la vía pública. En paralelo, los delitos contra la propiedad mostraron una tendencia de crecimiento aún más acentuada, pasando de 971 a 9.050 casos para el mismo período, con una mayor cantidad de hurtos que de robos ${ }^{15}$. Mientras las tasas de delito contra la propiedad y las personas mostraron una sostenida tendencia ascendente, la evolución de los arrestos por contravenciones -ebriedad, desórdenes y alteración pública- fue más oscilante, con momentos de expansión y contracción los que respondían a las fluctuaciones económicas, el estallido de huelgas, los conflictos políticos y los cambios en las prioridades policiales ${ }^{16}$.

En este contexto, las denuncias de delitos aumentaron a un ritmo más acelerado que los arrestos, y la tasa de detenidos por crimen cometido descendió notablemente a lo largo del período ${ }^{17}$. Ante esta situación, los contemporáneos llamaron la atención sobre la ineficacia de la policía, señalando la escasez de efectivos y la multiplicidad de funciones que éstos debían cumplir. En efecto, éstas excedían la vigilancia del orden público y la persecución de los delincuentes, abarcando diversos aspectos del mundo social, como la expedición de

\footnotetext{
12 Romero, José Luis, Breve historia de la Argentina, Fondo de Cultura Económica, Buenos Aires, 2005, p. 113-114.

13 Suriano, Juan, "Introducción: una aproximación a la definición de la cuestión social en Argentina" en Suriano, Juan (comp.), La cuestión social en Argentina, 1870-1943, La Colmena, Buenos Aires, 2000, p. 2-3.

14 Blackwelder, Julia Kirk \& Lyman L. Johnson, "Estadística criminal acción policial en Buenos Aires, 1887-1914”, Desarrollo Económico, Buenos Aires, vol. 24, n93, 1984, p. 114. Cabe aclarar que las estadísticas de la policía solamente reflejaban los delitos denunciados, de modo que estas cifras ocultan la cantidad de hechos delictivos que no llegaban a conocimiento de la institución policial.

15 Blackwelder, J. K. \& L. L. Johnson, “Estadística criminal”, Op. Cit., p. 114.

16 Blackwelder, J. K. \& L. L. Johnson, “Estadística criminal”, Op. Cit., p. 110-112

17 Caimari, L., Apenas un delincuente, Op. Cit., p. 81.
} 
documentos, la intervención en problemas de familia, la protección de niños y pobres y el cuidado del aspecto estético que debía reinar en la ciudad ${ }^{18}$.

Apremiados por incertidumbres e interrogantes sobre una sociedad cuya velocidad de transformación corría más rápido que la elaboración de instrumentos para su conceptualización, muchos miembros de las elites dirigentes encontraron en el saber criminológico una base desde la cual intentar responder a algunos de los enigmas más acuciantes de la hora ${ }^{19}$.

La criminología positivista surgió en Italia a finales del siglo XIX. Uno de sus fundadores fue el médico Cesare Lombroso, cuya obra L'uomo delincuente (1876) indagó las causas del delito a partir de un estudio individualizado del criminal. Influido por la teoría darwiniana, postuló una explicación biológica según la cual los delincuentes tenían una proclividad innata hacia el crimen, asociada a la reaparición de caracteres propios de ascendientes remotos (el atavismo $)^{20}$. Los discípulos de Lombroso ampliaron esta visión predominantemente antropológica. Así, Raffaele Garófalo acentuó los factores psicológicos y Enrico Ferri propuso causalidades del crimen que desplazaban lo biológico por lo ambiental. Lombroso también recibió la crítica de la escuela francesa de criminología, representada por autores como Gabriel Tarde y Alexandre Lacassagne, quienes rechazaron la hipótesis atávica y plantearon el predominio de las determinaciones sociales en los orígenes del delito ${ }^{21}$.

Estas ideas se apartaron de la escuela clásica del derecho penal vigente en Europa entre el siglo XVIII y la primera mitad del XIX ${ }^{22}$. Ésta caracterizó al delito desde un punto de vista jurídico, como la violación de una norma, y al delincuente como un ser racional, libre y responsable de sus propias acciones. De acuerdo a estos principios, la pena era un castigo proporcional al perjuicio social causado por la infracción, de modo que su atención se concentró en fijar una pena para cada delito, "sin hacer referencia a la naturaleza del individuo de que se trataba y sin considerar las circunstancias especiales de la comisión del acto" 23 .

Una de las novedades que aportó el positivismo consistió en el estudio científico de las causas de la criminalidad con el fin de individualizar las medidas adecuadas para extinguirlas

\footnotetext{
18 Ruibal, Beatriz, "El control social y la policía de Buenos Aires 1880-1920", Boletín del Instituto de Historia Argentina y Americana "Dr. Emilio Ravignani", Buenos Aires, n², 1990, p. 81.

19 Geli, Patricio, "Los anarquistas en el gabinete antropométrico. Anarquismo y criminología en la sociedad argentina del 900", Entrepasados, Buenos Aires, n², 1992, p. 22.

${ }^{20}$ Caimari, L., Apenas un delincuente, Op. Cit., p. 89.

${ }^{21}$ Caimari, L., Apenas un delincuente, Op. Cit., p. 89.

${ }^{22}$ Baratta, Alessandro, Criminología crítica y crítica del derecho penal: introducción a la sociología jurídico penal, Siglo XXI, Buenos Aires, 2004, p. 24.

${ }^{23}$ Taylor, Ian \& Walton, Paul \& Jock Young, La nueva criminología. Contribución a una teoría social de la conducta desviada, Amorrortu Editores, Buenos Aires, 1997, p. 23.
} 
o atenuarlas. Por otra parte, los positivistas reaccionaron contra el concepto abstracto del acto delictivo y procuraron reinsertar la acción del individuo en su contexto. En consecuencia, caracterizaron al delito como un fenómeno de índole natural y social. Las nociones de libre albedrío y responsabilidad individual de la escuela clásica fueron dejadas de lado y, en su lugar, postularon la existencia de una compleja trama de determinaciones biológicas y sociales que, lejos de permitir el ejercicio de la voluntad racional, conducían al individuo a cometer un delito. A la vez, asumieron una concepción de la pena como un medio de "defensa social", con el fin de proteger a la sociedad del peligro que representaban los individuos que no podían dominar sus tendencias criminales. También reemplazaron la noción de castigo por la idea de un tratamiento que aspiraba a la rehabilitación del sujeto, por lo que adoptaron los principios de individualización e indeterminación de las penas.

En la Argentina, la influencia de la escuela positivista se hizo sentir desde finales del siglo XIX. En 1888, miembros de la elite intelectual porteña como Norberto Piñero, Francisco y José María Ramos Mejía, Luis María Drago, José Nicolás Matienzo y Rodolfo Rivarola, fundaron la Sociedad de Antropología Jurídica, que aspiraba, por un lado, a "completar la ciencia europea con los datos de la antropología y la sociología argentinas y de la América indígena", y por otro, a "estudiar la personalidad del delincuente como base para preparar la reforma de las leyes penales" 24 . A partir de entonces comenzaron a publicarse libros y revistas especializadas que difundían y discutían los postulados de las nuevas teorías criminológicas $^{25}$. La producción intelectual de los criminólogos argentinos se incrementó, al tiempo que se estrecharon los contactos directos con sus colegas italianos, particularmente con figuras como Lombroso y Ferri.

Las aulas universitarias se convirtieron en ámbitos privilegiados para la enunciación de la teoría criminológica positivista. En la inauguración de su cátedra de Derecho Penal en la Universidad de Buenos Aires en 1887, Piñero aludió a las ideas del I Congreso de

\footnotetext{
${ }^{24}$ Del Olmo, R., América Latina, Op. Cit., p.135.

${ }^{25}$ Las primeras producciones fueron Principios fundamentales de la escuela positivista (1888), de Francisco Ramos Mejía, y Los hombres de presa (1888), de Luis María Drago, el cual fue elogiado y prologado en su edición italiana por el mismo Lombroso. A estos trabajos le siguió Las causas del delito (1892), de Antonio Dellepiane, que también contribuyó a dar señales del grado de adhesión que la nueva escuela encontró en la Argentina. Además, surgieron revistas: en 1898 se inició la publicación de Criminología Moderna, dirigida por el abogado italiano Pietro Gori, que contó con colaboraciones de Lombroso y Ferri y agrupó en su consejo de redacción a Dellepiane, Drago, Piñero, Rivarola y Vucetich. Por su parte, en 1902 José Ingenieros fundó los Archivos de Criminología y Psiquiatría, publicación que sirvió como punto de encuentro de criminólogos, higienistas y alienistas. A partir de 1913 fueron reemplazados por la Revista de Criminología, Psiquiatría y Medicina Legal. Al promediar la primera década del siglo XX, la producción nacional sobre criminología había alcanzado un volumen considerable. De esto da cuenta la "reseña bibliográfica" que Eusebio Gómez escribió en 1912 para su obra Criminología Argentina, que ofrecía un catálogo exhaustivo de lo publicado hasta ese momento. Tan sólo el capítulo sobre el debate teórico de las escuelas criminológicas recogía más de cien referencias locales, entre las que figuraban trabajos de Piñero, Drago, Dellepiane, Ingenieros, Francisco de Veyga, Miguel Lancelotti, Cornelio Moyano Gacitúa y el propio Gómez.
} 
Antropología Criminal celebrado en Roma en 188526. Por su parte, en 1897, la Facultad de Medicina de la misma Universidad inauguró el primer curso de Antropología y Sociología Criminal, dictado por el médico Francisco de Veyga.

La adopción de las enseñanzas de la antropología criminal se reflejó en la creación de los primeros gabinetes de identificación que comenzaron a funcionar en los cuarteles de policía. Surgieron también los Institutos de Criminología, organismos técnicos encargados del examen de la personalidad del delincuente en el seno de los centros penitenciarios. El primero de ellos se instaló en 1907 en el recinto de la Penitenciaría Nacional y contó con la dirección de José Ingenieros. Con ello, la Argentina se convirtió en el primer país en poner en práctica la criminología clínica en el campo penitenciario ${ }^{27}$.

A medida que se asimilaron las novedades teóricas europeas, se elaboraron algunos postulados novedosos, derivados del esfuerzo por adaptar las teorías extranjeras a las necesidades y las condiciones del contexto local. En este sentido, se destaca el aporte de Ingenieros, quien integró las explicaciones biológicas y sociales del crimen y las puso en relación con los factores psicológicos. Concibió así al acto delictivo como el resultado de una anomalía psicológica que reflejaba la incapacidad del delincuente para adaptarse a las normas sociales. Por esta vía, amplió los postulados de la antropología criminal y sentó las bases de un estudio psicopatológico del delincuente, que incorporaba el análisis de su estructura y funcionamiento psíquicos. Así, el proceso de incorporación de la matriz criminológica implicó apropiaciones y, al mismo tiempo, reformulaciones: las ideas fueron adaptadas a las condiciones del suelo nacional, adquiriendo entonces nuevos significados.

La recepción de estas novedades teóricas orientadas a interpretar los problemas de la sociedad no fue una tarea privativa de los criminólogos porteños. En efecto, algunos intelectuales del interior se hicieron eco de los cambios sociales y buscaron hacerlos comprensibles a la luz de registros innovadores. La obra de Cornelio Moyano Gacitúa es un claro signo de este fenómeno.

\section{Cornelio Moyano Gacitúa y la criminología positivista}

\subsection{Un perfil intelectual singular}

Cornelio Moyano Gacitúa nació en Córdoba en 1858 en una familia de marcado protagonismo en las luchas del período independiente ${ }^{28}$. Estudió en el Colegio de Monserrat

\footnotetext{
26 Del Olmo, R., América Latina, Op. Cit., p. 21.

27 Del Olmo, R., América Latina, Op. Cit., p. 153.

28 Los datos biográficos que siguen han sido tomados de Soler, Sebastián, Cornelio Moyano Gacitúa, Academia Nacional de Derecho y Ciencias Sociales, Córdoba, 1961.
} 
y en 1882 se doctoró en Leyes en la Facultad de Derecho de la Universidad Nacional de Córdoba. A partir de entonces desarrolló una carrera ascendente en la magistratura. A poco tiempo de egresar fue designado Juez de Paz Letrado y, posteriormente, Juez Federal de Córdoba. En 1902, al crearse la Cámara Federal de Apelaciones, fue uno de sus primeros integrantes, junto a los doctores Simeón Aliaga y Pablo Julio Rodríguez. En 1904 fue designado miembro de la comisión encargada de preparar la revisión del Código Penal. Al año siguiente, Gacitúa fue convocado por un ex alumno ilustre de Córdoba, Joaquín V. González - por entonces Ministro del Interior de la Nación-, para integrar la Corte Suprema de Justicia de la Nación. Ejerció esta magistratura hasta su muerte, en julio de 1911. Compartió ese ámbito con Octavio Bunge, Antonio Bermejo, Mauricio Pastor Daract y Nicanor González del Solar.

La carrera en la justicia sólo se vio brevemente interrumpida a comienzos de 1907, cuando fue designado interventor federal de la provincia de San Juan, con el fin de resolver la situación desatada por el movimiento revolucionario que desalojó del poder al gobernador Manuel José Godoy. Esa fue su única actuación en el campo de la política y por requerimiento del presidente José Figueroa Alcorta, con quien tenía una amistad forjada en sus épocas universitarias.

Su larga y constante actuación pública como magistrado se complementó con una prolongada trayectoria como docente de la Facultad de Derecho de la Universidad Nacional de Córdoba. Designado catedrático de Derecho Penal y Comercial en 1886, cubrió esa función durante dieciocho años, hasta que fue convocado para la Suprema Corte en 1905. En este período se dedicó intensamente al trabajo intelectual, que dio lugar a la publicación de dos tratados jurídicos de gran relieve: Curso de Ciencia Criminal (1899) y La delincuencia argentina (1905).

En suma, su derrotero profesional transcurrió en torno a dos ejes principales: por un lado, su vocación de administrar justicia a través del ejercicio de la magistratura y, por otro, la práctica de la docencia y la investigación, que lo definieron como un hombre de letras con un perfil especializado. Según Ana Clarisa Agüero, la trayectoria de Moyano Gacitúa presentó singularidades en comparación con otros representantes de su generación, porque se sustrajo de la carrera política y desarrolló una especialización jurídica en el terreno del derecho penal. Adquirió rasgos de especialista y como tal fue llamado a ocupar las posiciones más expectables de la escena jurídica nacional. Su despliegue intelectual fue más específico que genérico y su lugar en la jerarquía del poder -en el seno de la magistraturaderivó, ante todo, de su saber ${ }^{29}$.

29 Agüero, Ana Clarisa, "Trayectorias divergentes. Derecho, universidad y cultura en el giro de siglo cordobés", Miradas alternativas. Revista de ciencias sociales, Córdoba, n²4, 2008, p. 9. 


\subsection{Una recepción crítica del pensamiento criminológico}

En un contexto en el cual la Universidad de Córdoba comenzó a recibir fuertes críticas por su situación de atraso intelectual, Moyano Gacitúa propició la infiltración del espíritu científico en sus aulas ${ }^{30}$. Creía en la necesidad de convertir a la Universidad en una "casa de ciencia" con el fin de otorgar a los estudiantes - futuros dirigentes- nuevos instrumentos para comprender la realidad y responder a los desafíos que la sociedad argentina presentaba31. La enseñanza de la criminología positivista se revelaba como una herramienta útil para avanzar en este sentido. Por esa razón, en el programa de Derecho Penal correspondiente al año 1890 introdujo el estudio de los conceptos postulados por la escuela positiva sobre el delito, la pena y el sistema penitenciario. Junto a las teorías de la corriente italiana de criminología (Lombroso, Ferri y Garófalo), incorporó también a algunos exponentes de la corriente francesa $^{32}$. Así, mientras Moyano Gacitúa se mantuvo al frente de la cátedra, la enseñanza del derecho penal no quedó al margen de las innovaciones teóricas y metodológicas desarrolladas en el plano internacional ${ }^{33}$.

${ }^{30}$ Entre finales del siglo XIX y comienzos del XX, distintas voces comenzaron a manifestar su insatisfacción con respecto a la situación que presentaba la Universidad Nacional de Córdoba. En 1891, la Comisión de Presupuesto del Congreso Nacional propuso la supresión de dos de las tres facultades que integraban la casa de altos estudios cordobesa -las de Medicina y Ciencias Físico-Matemáticas. Los argumentos aducían el estado de decadencia de la institución y su reducida población estudiantil frente a los costos de su mantenimiento. En este marco, Ramón J. Cárcano -destacado exponente del liberalismo cordobés- señaló que las principales deficiencias se hallaban en la falta de compromiso de los profesores y las autoridades con la actividad académica. De acuerdo al marco estatutario que regulaba la vida universitaria desde la década de 1880, la selección de los profesores no descansaba en sus méritos ni aptitudes, sino en sus servicios o adhesiones políticas. Según Cárcano, esto redundaba en una enseñanza arcaica y dogmática. Otros sectores, en cambio, colocaron el énfasis en cuestiones ideológicas y doctrinarias para explicar las debilidades de la enseñanza impartida en la institución. En efecto, una parte relevante de las acusaciones que lanzaron los protagonistas del movimiento reformista de 1918 señalaron que la Universidad cordobesa era un remedo de la antigua institución clerical implantada durante la colonia. Cárcano, Ramón J., Universidad de Córdoba. Algunas palabras sobre su organización, Félix Lajouane, Buenos Aires, 1892; Agüero, Ana Clarisa, "Comunidades, circuitos y lugares relativos en la cultura nacional. Caída y reparación de Córdoba entre dos generaciones (1880-1920)" en Laguarda, Paula \& Flavia Fiorucci (eds.), Intelectuales, cultura y politica en espacios regionales de Argentina (siglo XX), Prohistoria, Rosario, 2012, p. 55-77; Buchbinder, Pablo, ¿ Revolución en los claustros? La Reforma Universitaria de 1918, Editorial Sudamericana, Buenos Aires, 2008; Buchbinder, Pablo, "Controversias sobre la vida universitaria entre el antiguo régimen y la Reforma" en Saur, Daniel \& Alicia Servetto (coords.), Universidad Nacional de Córdoba. Cuatrocientos años de bistoria, tomo II, Universidad Nacional de Córdoba, Córdoba, 2013, p. 11-25.

${ }^{31}$ Moyano Gacitúa, Cornelio, La Universidad en la época actual, La Patria, Córdoba, 1903.

32 Facultad de Derecho y Ciencias Sociales de la Universidad Nacional de Córdoba, Programa de Derecho Penal para el año 1890, La Minerva, Córdoba, 1890.

${ }^{33} \mathrm{La}$ incidencia del positivismo francés se puede corroborar en los catálogos de obras que la Facultad de Derecho comenzó a requerir para las colecciones de la Biblioteca de la Universidad, en donde se añadieron títulos como La philosophie pénale, de Tarde, y Le crime et la peine, de Louis Proal, véase: Archivo General e Histórico de la Universidad Nacional de Córdoba (AGHUNC), Serie Documentos, libro 29, 1899, fs. 11-12v. En este mismo sentido, puede destacarse la propuesta de creación de un curso de clínica criminal presentada en 1892 a la Facultad de Derecho por Antonio del Viso y Ponciano Vivanco. El proyecto se fundó en los postulados del I Congreso Internacional de 
Fuera de la labor docente, la criminología positivista también le ofreció una batería de postulados y métodos factibles de ser aplicados en su propia producción intelectual. Quizás esto explica el reconocimiento que recibió de destacados referentes de dicha corriente en el ámbito nacional e internacional. La introducción de su obra Curso de Ciencia Criminal fue escrita por Osvaldo M. Piñero -quien por entonces había sucedido a su tío, Norberto Piñero, en la cátedra de Derecho Penal en la Universidad de Buenos Aires. Allí, el profesor porteño señalaba: "En las páginas hermosas y llenas de buena erudición de esta obra, el lector investigador verá desfilar las tentativas audaces del espíritu científico para explicar el delito y las causas individuales y sociales que lo determinan" 34 . Por su parte, el mismo Lombroso escribió una carta a Moyano Gacitúa en la que señalaba que su libro, La delincuencia argentina ante algunas cifras y teorías, era "el más importante de Sociología y Antropología Criminal aparecido en estos dos últimos años y en ambos mundos"35. Años más tarde, Eusebio Gómez valoró los aportes del trabajo de cuantificación desarrollado por Moyano Gacitúa en esa obra, asegurando que -junto con los materiales elaborados por el Instituto de Criminología y el censo carcelario de 1906- contribuía a delinear los rasgos distintivos de la criminalidad en el país ${ }^{36}$.

En general, los estudios dedicados a analizar la filiación teórica de Moyano Gacitúa señalaron que el autor no manifestó una adhesión absoluta a los postulados del positivismo. En 1910, Rodolfo Rivarola -profesor de Derecho Penal de la Universidad Nacional de La Plata y compañero de Moyano Gacitúa en la comisión encargada de redactar el proyecto de reforma de Código Penal en 1906- señaló que su colega cordobés "ha explicado y aceptado muchas ideas de la escuela positivista de derecho penal, pero ha sostenido a la vez el libre albedrío" 37 . En un tono similar, el jurista español Luis Jiménez de Asúa lo calificó como uno

\footnotetext{
Antropología Criminal, celebrado en Roma en 1885, en donde se discutieron a fondo las principales ideas de la escuela positivista italiana y se recomendó la enseñanza de la clínica criminal. Véase: Archivo Histórico de la Facultad de Derecho y Ciencias Sociales (AHFDCS), Actas de sesiones, año 1892, f. 176. La difusión de las nuevas teorías criminológicas en la universidad cordobesa puede ser observada, además, en las tesis de los estudiantes de derecho. Éstas son demostrativas de los conocimientos que recibieron e incorporaron en las aulas. Como señala Marcela González, las tesis abordaron las causas de la delincuencia, los factores de delito y los sistemas penitenciarios, observándose la preocupación de los jóvenes por la modificación de los criterios y sistemas vigentes, ponderando una metodología preventiva sobre las acciones punitivas. El análisis de la temática manifiesta la atracción que ejercieron cuestiones relacionadas con el medio social del individuo delincuente. Sobre las tesis de derecho, véase: González, Marcela, "El medio, los actores y las ideas en la Universidad de Córdoba, 1900-1910", Studia, Córdoba, n5, 1996, p. 175-224. Con respecto a las representaciones sobre el delito, la pena y los sistemas penitenciarios en las tesis de doctorado de la Facultad de Derecho, véase: Luciano, Milena, "Las ideas penitenciarias en el campo jurídico cordobés. 1885-1911”, Anuario de la Escuela de Historia Virtual, Córdoba, n4, 2013, p. 75-92.

34 Moyano Gacitúa, Cornelio, Curso de Ciencia Criminal y Derecho Penal Argentino, Félix Lajouane, Buenos Aires, 1899, p. XXXIII.

35 Moyano Gacitúa, Cornelio, La delincuencia argentina ante algunas cifras y teorías, Buena Vista, Córdoba, 2012, p. 4.

${ }^{36}$ Gómez, Eusebio, Criminología argentina, Librería e Imprenta Europea, Buenos Aires, 1912, p. X.

37 Rivarola, Rodolfo, Derecho Penal Argentino, Librería Rivadavia, Buenos Aires, 1910, p. 35.
} 


\section{Revista Historia y Justicia}

de los "introductores del positivismo" en la Argentina, pero advirtió que en sus obras "sustentó una inteligente combinación de presupuestos clásicos y positivistas"38.

En un homenaje a Moyano Gacitúa realizado en 1961 en la Academia Nacional de Derecho y Ciencias Sociales de Córdoba, el penalista Sebastián Soler analizó más profundamente la postura teórica del profesor cordobés. Por un lado, observó que éste mantuvo su adhesión al principio clásico de la responsabilidad penal basada en la libre voluntad del individuo. De hecho, en su Curso de Ciencia Criminal caracterizó al delito con una fuerte impronta racionalista, como una "violación consciente" de las normas de conducta necesarias para la vida social ${ }^{39}$. Entendía que el delincuente era un individuo libre y racional, capaz de actuar de manera deliberada y en pleno ejercicio de su voluntad. La acción delictiva era un producto del comportamiento del hombre en ejercicio de su libre arbitrio.

Sin embargo, Soler advirtió que la criminología positivista le reveló un método experimental para investigar los factores causales del delito. Como sucedió con otros criminólogos argentinos de la época, "lo que lo seduce es mucho más el planteamiento de los problemas y el método seguido que las soluciones o conclusiones alcanzadas; le atrae la dirección científica cuya novedad lo llena de esperanzas"40.

Más recientemente, y desde la historia del derecho, José Daniel Cesano examinó las operaciones de selección que Moyano Gacitúa realizó en el proceso de recepción de la criminología positivista, contribuyendo a precisar mejor su relación con las nuevas ideas ${ }^{41}$. En este sentido, coincidió con el diagnóstico de Soler al señalar que la escuela fundada por Lombroso ejerció una indudable influencia sobre su pensamiento, lo que se puso de manifiesto, sobre todo, en la aplicación de un método de indagación. Además, Cesano observó esta afinidad en la definición de una agenda temática -que problematizó tópicos como el anarquismo o la raza- y la adopción del principio de defensa social ${ }^{42}$. Sin embargo, advirtió que el jurista cordobés distó de plegarse enteramente al darwinismo social y además rechazó las explicaciones antropológicas para priorizar el examen de los factores sociales.

Las reservas de Moyano Gacitúa con respecto a algunas premisas de la tradición italiana se inspiraron, en gran parte, en las obras de la corriente positivista francesa, que ejercieron una fuerte influencia en su desarrollo conceptual. En este sentido, Cesano constató que los postulados de criminólogos como Gabriel Tarde, Louis Proal y Henry Joly tuvieron una importante presencia en sus obras, como citas de autoridad que sustentaron sus críticas a la escuela italiana. A la luz de este planteo puede observarse, por ejemplo, el influjo de las ideas

38 Jiménez de Asúa, Luis, Tratado de Derecho Penal, tomo I, Editorial Losada, Buenos Aires, 1950, p. 880.

39 Moyano Gacitúa, C., Curso de Ciencia Criminal, Op. Cit., p. XXXVIII.

${ }^{40}$ Soler, S., Cornelio Gacitúa, Op. Cit., p. 21.

${ }^{41}$ Cesano, J. D., Élites, Op. Cit., p. 46-51.

${ }^{42}$ Cesano, J. D., Élites, Op. Cit. 
de Tarde en los cuestionamientos de Moyano Gacitúa a los fundamentos de la teoría lombrosiana: en su Curso de Ciencia Criminal se basó en el autor francés para señalar que las anomalías encontradas por Lombroso en la anatomía de los delincuentes no habían sido corroboradas por los estudios experimentales de gran cantidad de criminólogos que, incluso, habían llegado a conclusiones enteramente distintas ${ }^{43}$. Observó, además, que el estudioso turinés había tratado los rasgos de los "criminales natos" como los de una especie singular, sin considerar que éstos también podían hallarse en los hombres no delincuentes. Cuestionó asimismo que las anomalías del tipo criminal detectadas por Lombroso sólo habían sido constatadas en un $40 \%$ de los delincuentes examinados, una proporción insuficiente para afirmar su generalidad ${ }^{44}$. En todo caso, si los criminales exhibían algunos rasgos físicos particulares -como cicatrices, mirada "fugitiva y huraña", o brazos y mandíbulas fuertes-, éstos obedecían a su modo de vivir; no eran adquiridos por herencia sino que reconocían un origen social. Moyano Gacitúa también se apoyó en Tarde para cuestionar la teoría del atavismo, señalando que aquel autor había demostrado la existencia de sociedades primitivas "inclinadas comúnmente al bien", por lo que no podía constatarse que todos los "salvajes" tuvieran tendencias criminales ${ }^{45}$.

En suma, los distintos análisis sobre la filiación teórica de Moyano Gacitúa permiten concluir que el profesor cordobés incorporó de manera crítica las enseñanzas del positivismo criminológico italiano, al tiempo que introdujo elementos de la corriente positivista francesa y conservó ciertas ideas de la escuela clásica. De esta manera, no puede ser conceptualizado como un intelectual ortodoxo, pues su pensamiento se caracterizó por visitar distintas tradiciones teóricas sin inscribirse plenamente en ninguna de ellas. Lejos de la cómoda y pasiva reproducción de un marco teórico único, su obra exhibió cierta flexibilidad y complejidad que lo colocaron en una posición más cercana al eclecticismo.

\section{El uso de la cuantificación para el estudio empírico de la delincuencia}

Como se ha podido observar, existe consenso en señalar que Moyano Gacitúa adhirió al enfoque metodológico de la criminología positivista. El positivismo sostuvo que el conocimiento objetivo de la realidad social podía lograrse mediante la aplicación del método de las ciencias naturales. Desde esta postura, los criminólogos positivistas desplazaron al razonamiento abstracto, formal y deductivo de la escuela clásica y propusieron un método empírico basado en la observación y la inducción.

El mismo Moyano Gacitúa declaró sentirse "apasionado por ese movimiento científico" y en La delincuencia argentina aplicó esta metodología, apelando a la cuantificación para analizar

\footnotetext{
${ }^{43}$ Moyano Gacitúa, C., Curso de Ciencia Criminal, Op. Cit., p. 118-119.

${ }^{44}$ Moyano Gacitúa, C., Curso de Ciencia Criminal, Op. Cit., p. 126.

45 Moyano Gacitúa, C., Curso de Ciencia Criminal, Op. Cit., p. 131.
} 
las causas específicas del comportamiento delictivo en el país ${ }^{46}$. Al decir de Cesano, una "actitud científica" tiñó todo su estudio sobre la cuestión criminal: "su investigación es muy compleja y se encuentra apoyada en el cúmulo de información estadística que emplea (...) en esta faena, Moyano Gacitúa debe considerarse un precursor" ${ }^{47}$.

No obstante, aún resta indagar ¿por qué le asignó centralidad al análisis cuantitativo, qué fuentes empleó, cómo construyó sus cifras y qué conclusiones derivó del examen de las mismas? Las siguientes páginas intentarán realizar un aporte al esclarecimiento de estos interrogantes, con el propósito fundamental de establecer cuáles fueron las implicancias del desarrollo de la metodología cuantitativa en el estudio de la etiología criminal.

\subsection{Cifrar el cuerpo social: evidencias y expectativas}

En la Argentina, la recopilación estadística sobre los actos delictivos comenzó a ser desarrollada por la policía en la década de 1860. Esta tarea quedó formalizada en 1875, cuando se creó la Oficina de Estadística Criminal en el seno de la institución policial. Al mismo tiempo, desde su inauguración en 1877, la Penitenciaría Nacional incorporó en sus memorias registros cuantitativos de los encausados y los condenados, clasificados según edad, estado civil, grado de instrucción y nacionalidad. En 1894, una ley promovió la centralización administrativa del sistema estadístico nacional mediante la creación de la Dirección General de Estadística, la cual debía concentrar todas las materias sobre las que se elaboraban estadísticas en el país: movimiento demográfico, comercio exterior, inmigración, instrucción, ferrocarriles, movimiento policial, criminal y carcelario ${ }^{48}$. En la práctica, sin embargo, la institución policial mantuvo su servicio estadístico en materia delictiva.

Durante la última década del siglo XIX, las series de datos difundidas por la policía comenzaron a recibir severas críticas. En 1886, Francisco Latzina, director del Departamento Nacional de Estadística, cuestionó los datos policiales por sus variaciones en la forma de compilación y los errores de cálculos que podían encontrarse año a año ${ }^{49}$. Algunos juristas también comenzaron a señalar que los números de la policía eran limitados y poco rigurosos. En un artículo publicado en 1893 en el diario porteño La Nación, Osvaldo Piñero denunció que las estadísticas sólo consignaban los delitos perseguidos por la policía, mientras que otros hechos sancionados por la legislación penal (como estafas, defraudaciones, malversación de

\footnotetext{
46 Moyano Gacitúa, C., La delincuencia, Op. Cit., p. 50.

${ }^{47}$ Cesano, José Daniel, "Cornelio Moyano Gacitúa: su pensamiento en la tradición criminológica Argentina (18991905)” en Moyano Gacitúa, C., La delincuencia, Op. Cit., p. 44.

48 Daniel, Claudia, "Medir la moral pública. La cuantificación policial del delito en Buenos Aires, 1880-1910", Estatística e Sociedade, Porto Alegre, nº1, 2011, p. 152-153.

${ }^{49}$ Daniel, C., "Medir la moral", Op. Cit., p. 153. Sobre la trayectoria de Latzina, véase González Bollo, Hernán, "Francisco Latzina (1843-1922), funcionario estadístico del Estado argentino (1880-1916)", Estatística e Sociedade, Porto Alegre, n³, 2013, p. 110-121.
} 
fondos públicos, abuso de autoridad, violaciones a los deberes de funcionario público) permanecían ausentes. A ello puede agregarse que las cifras ponían énfasis en discriminar el lugar de procedencia de los delincuentes, reforzando la asociación entre delincuencia e inmigración, que era preconcebida desde el sentido común policial ${ }^{50}$. Por otra parte, la información era incorporada de maneras irregulares y variables a lo largo del tiempo y arrastraba los problemas propios de toda representación institucional que intentaba dar cuenta de su propia eficacia ante el Ministerio al que informaba, y, por ende, era objeto de muchas manipulaciones ${ }^{51}$.

En este contexto, en su obra de 1905 Moyano Gacitúa procuró cuantificar los factores de la criminalidad para elaborar explicaciones sobre la delincuencia en la Argentina. El autor reconocía su carácter de precursor en una tarea que hasta entonces no había sido emprendida de manera sistemática por la criminología argentina ${ }^{52}$ :

"Este libro, es apenas el primer golpe de hacha dado por el pioner que desmonta una selva virgen (...) Es útil recordar que nadie ha tratado en el país esta materia, no para reivindicar el mérito de sus primicias, sino para concurrir a aquel ambiente de indulgencia que tanto necesita el autor y que es consecuencia de la falta de precedentes. Quizás algún artículo de diario habrá insinuado datos sobre ella y allegado alguna observación estadística muy apreciable, pero de simple detalle; quizás escritores de otra índole habrán suministrado sus juicios sobre la naturaleza de nuestra criminalidad; pero un cuerpo sistemado(sic) de doctrina sobre ella no existe entre nosotros" ${ }^{\prime 53}$.

${ }^{50}$ Como señala Hernán Olaeta, los números que construía la policía no hacían más que "ayudar a consolidar el modelo de criminalidad perseguido por las agencias de control social." Olaeta, Hernán, "Surgimiento de las estadísticas criminales en Argentina. La influencia de los discursos criminológicos en la producción y análisis de datos de la Ciudad de Buenos Aires (1885-1921)", Delito y Sociedad. Revista de Ciencias Sociales, Buenos Aires, vol. 2, $\mathrm{n}^{\circ} 40,2015$, p. 42.

${ }^{51}$ Caimari, Lila, Mientras la ciudad duerme. Pistoleros, policias y periodistas en Buenos Aires, 1920-1945, Siglo XXI, Buenos Aires, 2012, p. 29.

52 En el ámbito internacional, esta empresa registraba un antecedente en la obra del criminólogo francés Gabriel Tarde, que en 1883 había publicado en la Revue Pbilosophique un artículo titulado "La statistique criminelle du derniere demi-siècle". En el plano nacional, uno de los primeros intentos de analizar las estadísticas criminales fue realizado por Norberto Piñero en Problemas de criminalidad (1888), donde utilizó fuentes policiales para constatar el aumento del delito y señalar su relación con el crecimiento de la población extranjera. Ver Sozzo, Máximo, “'Los exóticos del crimen'. Inmigración, delito y criminología positivista en la Argentina (1887-1914)”, Delito y Sociedad. Revista de Ciencias Sociales, Buenos Aires, vol. 2, n³2, 2011, p. 30. Luego de los aportes de Moyano Gacitúa, el interés por el análisis estadístico de la cuestión criminal fue retomado por Miguel Lancelotti en su obra La criminalidad en Buenos Aires de 1885 a 1910. Al margen de la estadística (1912); sobre este autor, véase Cesano, José Daniel \& Jorge Alberto Núñez, "La criminalidad en Buenos Aires de Miguel A. Lancelotti: Una aproximación contextual al autor y su obra" en Cesano, José Daniel \& Jorge Alberto Núñez, Visiones de la criminología argentina (1903-1924). Una aproximación historiográfica, Editorial Brujas, Córdoba, 2014, p. 41-76.

${ }^{53}$ Moyano Gacitúa, C., La delincuencia, Op. Cit., p. 49. 
En el prólogo, Moyano Gacitúa agradeció al Rector de la Universidad, a su "invariable amigo" Ramón J. Cárcano, y al gobernador de Córdoba, José Manuel Álvarez. También mencionó a quienes le habían facilitado el acceso a estadísticas oficiales, como Guillermo Correa, ex gobernador de Catamarca, Adolfo Lazcano, intendente de La Plata, y Juan Vucetich, Director de la Oficina de Identificaciones de Buenos Aires. Finalmente, expresó su gratitud hacia todos aquellos que le habían remitido cifras "con la más exquisita amabilidad", como Juan Bialet Massé, que lo hacía desde Rosario. Estos elementos sugieren el papel, nada desdeñable, que los vínculos sociales ejercieron en el acceso a la información ${ }^{54}$. Es posible, además, que la recopilación de estos datos haya sido facilitada por el nombramiento de Moyano Gacitúa como miembro de la comisión encargada de elaborar el proyecto de reforma del Código Penal en 1904. De hecho, el decreto de designación le otorgaba la facultad de dirigirse a todas las reparticiones públicas del Poder Ejecutivo, el Ministerio de Justicia e Instrucción Pública, los gobiernos provinciales, tribunales y dependencias del Poder Judicial y del Poder Legislativo para requerir la información considerada necesaria para ilustrar su juicio ${ }^{55}$.

El corpus de fuentes empleado por Moyano Gacitúa estuvo compuesto principalmente por la documentación oficial proveniente de estos organismos estatales. En particular, se valió del Anuario Estadístico de la Ciudad de Buenos Aires que recogía las cifras producidas en la Policía de la Capital, y de los anuarios estadísticos de las provincias de Córdoba, Tucumán, Santa Fe, Buenos Aires, Catamarca, San Luis, Mendoza y San Juan. A ello se añadieron los datos provenientes de memorias ministeriales y de los censos nacionales de 1869 y 1895. Además, hizo uso de ciertos estudios demográficos nacionales, como La inmigración europea en

\footnotetext{
${ }^{54}$ Aún no existen trabajos que indaguen en las redes intelectuales que Moyano Gacitúa mantuvo con otros actores de la cultura científica argentina e internacional. Estos agradecimientos indican la existencia de un contacto entre estas figuras, pero no son suficientes para constatar una relación efectiva ni, mucho menos, para reconstruir el contenido y la intensidad de la misma. Una idéntica observación podría aplicarse a otros personajes de la escena intelectual, como Joaquín V. González, Osvaldo Piñero y el mismo Cesare Lombroso. El análisis relacional procura rescatar los vínculos existentes entre los actores sociales sobre la base de redes de relaciones diversas y superpuestas que permiten la circulación de bienes y servicios materiales e inmateriales, moldean los comportamientos y contribuyen a explicar las estrategias individuales. Por ende, considerar el conjunto de relaciones establecidas entre Moyano Gacitúa y otras figuras intelectuales tendría una gran potencialidad para reconstruir problemas relativos a la circulación de ideas y derivar explicaciones sobre su forma particular de analizar el fenómeno delictual. No obstante, la principal dificultad para reconstruir tales relaciones de manera densa y profunda reside en la ausencia $O$ el silencio de las fuentes que hasta el momento han podido relevarse. En tal sentido, se hace necesario contar con correspondencia epistolar, una fuente fundamental que aporta información privilegiada sobre las relaciones entre actores sociales: los intercambios que se movilizan a través de ellas, las funciones y atributos de cada vínculo, así como otros elementos referidos a los valores e ideas con los que actúan y se relacionan los actores sociales. Ver Imízcoz, José María, "Actores, redes, procesos: reflexiones para una historia más global”, Revista da Facultade de Letras. Historia, Porto, n5, 2004, p. 136.

55 Proyecto de Código Penal para la República Argentina, Tipografía de la Cárcel de Encausados, Buenos Aires, 1906, p. XI-XII.
} 
la República Argentina (1898), de Juan A. Alsina, y La Argentina considerada en sus aspectos físico, social y económico (1902), de Latzina.

El profesor cordobés señaló con frecuencia los inconvenientes creados por la escasez de estadísticas y la baja confiabilidad de las cifras disponibles en el país. Sobre esta cuestión, advirtió que no pocas veces los registros eran realizados "por empleados inconscientes, deseosos de llenar renglones y carillas para constatar una falsa labor" 56 . En materia de categorías socio-profesionales, observó que los censos nacionales aplicaban distintos criterios para recoger información y elaborar clasificaciones, situación que se repetía en las estadísticas provinciales. Las dificultades se agravaban en la compilación de información estadística de los medios rurales, pues la vastedad del territorio y la descentralización administrativa generaban un problema de subregistro que impedía conocer con certeza la cantidad de delitos.

Para intentar subsanar estas falencias hizo uso de la estadística procesal, la cual no estaba basada en las detenciones policiales sino en los juicios. Para construir estas cifras era necesario investigar los archivos y los libros de los tribunales, tarea que demandaba mayor tiempo y dificultad para descomponerlas e interpretarlas. No obstante, aseguraba que estos datos representaban "las fuentes puras de observación", porque se elaboraban con mayor exactitud y rigurosidad que las estadísticas policiales. Además, esas cifras le permitían establecer comparaciones con Europa, pues gran parte de las agencias estadísticas europeas se basaban en información procesal.

Moyano Gacitúa estimaba que la información cuantitativa era un insumo básico para elaborar argumentaciones de estricto rigor científico. La cuantificación permitía establecer relaciones entre extensas series de datos que daban cuenta de la repetición de los fenómenos de una misma naturaleza. Sobre esta base, creía en la posibilidad de elaborar una explicación causal a partir de la formulación de leyes generales. Se trataba de hacer inteligibles las causas del fenómeno por medio de la subsunción de los casos individuales en regularidades de carácter universal:

"la ciencia estadística que nos ayuda a interpretar las cifras, nos enseña que su mayor eficacia científica se encuentra en la dilución de esas cifras dentro de los grandes números, porque son precisamente ellos los que suministran mejor la verdad científica; y esto debido como se sabe, a que sólo dentro de la gran repetición de hechos en relación con otros hechos y fenómenos, surgen conclusiones a que se da nombre de leyes ${ }^{\text {"57 }}$.

Para el jurista cordobés, esta metodología revestía una eficacia incuestionable para el análisis de la delincuencia. Cifrar el cuerpo social parecía asegurar la posibilidad de

56 Moyano Gacitúa, C., La delincuencia, Op. Cit., p. 53.

${ }^{57}$ Moyano Gacitúa, C., La delincuencia, Op. Cit., p. 328 
diagnosticar las causas del problema y guiar las intervenciones para su resolución. Si la sociedad se entendía como un organismo, las estadísticas ofrecían la "mesa de disección" desde la cual realizar observaciones, generar evidencias, construir conocimientos y diseñar tratamientos ${ }^{58}$. Los datos recolectados permitirían conocer las condiciones del medio en que se desarrollaba la vida del delincuente y establecer las causas sociales de la criminalidad, para luego dirigir la acción del legislador con relación a las mismas.

Además, las cifras le resultaban atractivas para componer una imagen más completa y certera tanto de la magnitud del problema del delito en la Argentina como de los factores específicos que incidían en su desarrollo en el suelo nacional. Como señaló en su Curso de Ciencia Criminal, el delito no podía tratarse como una abstracción, porque era el resultado del modo de ser colectivo de cada pueblo y de cada época ${ }^{59}$. La preocupación debía centrarse entonces en develar las dimensiones y las causas de una "delincuencia específica nacional, hija de sus instituciones, de su constitución, de su sociabilidad y de la ubicación" 60 .

Como él mismo explicó, el procedimiento consistía en "empezar considerando las observaciones hechas a su respecto por algunos escritores extranjeros", es decir, "consignar las cifras estadísticas que nos vienen de Europa" y, posteriormente, compararlas con las que arrojaban las estadísticas nacionales, con el fin de reunir "todos los antecedentes de juicio necesarios antes de deducir las consecuencias aplicables en nuestro país." Este interés cientificista por indagar las particularidades que el fenómeno delictivo asumía en la realidad argentina explica, en gran parte, la relación crítica que Moyano Gacitúa mantuvo con las teorías importadas de Europa:

"El estudio de estos particularismos nacionales es por otra parte una justa y necesaria reacción sobre el antiguo método rutinario, erróneo e inconsistente, del que tanto se ha abusado de estudiar y aplicar a esta nación joven las instituciones y conclusiones científicas, políticas, industriales, etc., de otros países, sin ningún miramiento a sus especialidades. Hoy se ha impuesto por ley de reacción el método contrario, pero desconfiado como soy de que la reacción no se quede en su justo límite, porque es también su ley excederse y pasar más allá, he de procurar tenerlo en cuenta combinando, de la mejor manera posible, la consideración de cada una de las principales características que el país ofrece a estudio, con las observaciones que se encuentran en las obras científicas de otros países, principalmente europeos, porque ellos importan la experiencia, la verdadera observación científica, de la cual no es posible ni justo prescindir en trabajos de esta índole" ${ }^{\text {61 }}$.

\footnotetext{
58 Moyano Gacitúa, C., La delincuencia, Op. Cit., p. 51.

59 Moyano Gacitúa, C., Curso de Ciencia Criminal, Op. Cit., p. 55.

${ }^{60}$ Moyano Gacitúa, C., La delincuencia, Op. Cit., p. 70.

61 Moyano Gacitúa, C., La delincuencia, Op. Cit., p. 161.
} 
De esta manera, Moyano Gacitúa subrayaba el error de incorporar acríticamente las conclusiones científicas elaboradas para otros espacios. En lugar de realizar una simple aplicación de las ideas criminológicas foráneas, postulaba que ellas debían ser sometidas a verificación a la luz de las evidencias empíricas locales.

En una recensión de la obra de Moyano Gacitúa publicada en la Revista de Letras y Ciencias Sociales, el joven abogado tucumano Juan B. Terán cuestionó la presencia de algunas cifras erróneas -como la correspondiente a la población urbana de Tucumán-, lo que le suministraba la prueba de que la estadística no era un instrumento de absoluta precisión. Sin embargo, Terán destacó los resultados de una investigación que, lejos de "la erudición apoplética y la hinchazón libresca del pensamiento parasitario", estudiaba el problema de manera directa y en el terreno nacional ${ }^{62}$. No dudó en juzgar la obra como "un libro de sociología aplicada", con un alto contenido científico e interés político ${ }^{63}$. A diferencia de la generalidad de las producciones académicas de la época, que sólo realizaban alegatos fundados en citas extranjeras y definiciones teóricas, el trabajo de Moyano Gacitúa le resultó meritorio por su interés en explicar los hechos sobre la base de un escrutinio meticuloso de números que daban cuenta de manera concreta de las dimensiones particulares y genuinas de la realidad social argentina.

\subsection{Los hallazgos del análisis cuantitativo}

El estudio de la delincuencia a través de las evidencias cuantitativas, seguido por Moyano Gacitúa, hizo posible (1) contrastar empíricamente ciertos argumentos sobre las causas de la delincuencia en la Argentina; (2) discutir algunas nociones que encarnaban prejuicios o valoraciones subjetivas, y (3) elaborar nuevos postulados sobre el mundo social. Esto se manifestó muy especialmente en sus conclusiones sobre los escenarios del delito, la incidencia de la inmigración y los sectores sociales asociados a la delincuencia.

En primer lugar, Moyano Gacitúa observó que los índices de delincuencia permanecían relativamente bajos en las zonas rurales. Esta constatación puso en cuestión la vigencia de opiniones de larga data sobre la campaña como un espacio favorable para el desarrollo del delito:

"El juicio que antes se tenía formado era enteramente diverso; la ineducación del hombre rural, la dificultad de vigilarlo, la escasez de autoridades, el ambiente social semibárbaro o inculto por lo menos, que allí le envuelve, la soledad, el bosque o el desierto, todo parecía favorecer la propagación y reiteración del crimen, y ser como escenario donde se desarrollasen con preferencia los dramas delictuosos. (...) Pero la ciencia y la observación ban venido a desvanecer este error, e imputar a las ciudades centros populosos y de mayor cultura una

62 Terán, Juan B., Estudios y Notas, tomo I, Universidad Nacional de Tucumán, Tucumán, 1980, p. 85.

63 Terán, J. B., Estudios y Notas, Op. Cit., p. 86. 


\section{Revista Historia y Justicia}

ISSN 0719-4153 revista.historiayjusticia.org

N8 - Santiago de Chile, abril 2017, p. 166-194

acción criminógena mucho más extensa que aquella. (...) hoy el modo de vivir rural es el que da menos índices a la criminalidad, y su moralidad resulta de tal manera acentuada, que llega hasta ser la campaña uno de los atenuantes cuantitativos más importantes de los que la ciencia reconoce hoy día" ${ }^{\prime 64}$.

Las evidencias constataban que el fenómeno delictivo resultaba menos frecuente en el mundo rural que en las ciudades. Esto significaba que la vida urbana multiplicaba y complejizaba las relaciones sociales; el creciente "roce entre un hombre y otro" incrementaba la ocurrencia de tensiones y conflictos que culminaban en episodios delictivos. Además, la concentración de la población reducía las posibilidades de encontrar colocación en el mercado laboral, a partir de lo cual la subsistencia se dificultaba, las condiciones de vida se tornaban precarias y ello no tardaba en generar un aumento del hurto. El encarecimiento de los alimentos, los bajos salarios y la falta de remuneración también contribuían a ese resultado ${ }^{65}$.

Además, Moyano Gacitúa observó que las ciudades no sólo promovían el aumento numérico de la delincuencia, sino también una modificación de su naturaleza. En contraposición al medio rural, en el mundo urbano el homicidio cedía gradualmente su lugar a los hurtos, los robos y las estafas. Ante estas evidencias, apeló a la ley de criminalidad desarrollada por Lombroso, según la cual a una mayor densidad poblacional le correspondía un aumento de los delitos contra la propiedad y una disminución de los homicidios. A la inversa, el crimen de sangre aumentaba y los hurtos perdían gravitación a medida que se reducía la densidad poblacional y crecía la despoblación ${ }^{66}$.

En segundo lugar, el análisis estadístico de la delincuencia le permitió revisar la influencia de la inmigración en las tasas delictivas. En un país como la Argentina, donde el fenómeno inmigratorio asumió una magnitud tan importante, muchas lecturas marcaban el peso de la población extranjera en la creciente criminalidad urbana ${ }^{67}$. De acuerdo con estas visiones, el aluvión inmigratorio favorecía la penetración de una serie de males, vicios y modalidades de transgresión hasta entonces desconocidos en el suelo nacional. Los datos extraídos de los censos nacionales de 1869 y 1895 marcaban el predominio de italianos y españoles entre los inmigrantes arribados al país. Estas nacionalidades tenían la particularidad de encabezar los índices delictivos de Europa, lo cual facilitó el establecimiento de una correlación simple y lineal entre esta inmigración de "raza latina" y los altos índices de criminalidad.

\footnotetext{
${ }^{64}$ Moyano Gacitúa, C., La delincuencia, Op. Cit., p. 260-261. El destacado me pertenece.

65 Moyano Gacitúa, Cornelio, Notas de filosofía penal sobre el anarquismo, Imprenta La Patria, Córdoba, 1894, p. 13.

${ }^{66}$ Dentro del ámbito nacional, Moyano Gacitúa encontró algunos casos que escapaban de dicha regularidad. En Tucumán, por ejemplo, detectó un alto índice de delitos de sangre, a pesar de la gran densidad poblacional que acusaba la provincia. Esta particularidad fue explicada a partir de su condición de centro industrial y la intensificación de la vida social que ello provocaba.

${ }^{67}$ Zimmermann, E., Los liberales, Op. Cit., p. 126.
} 
Sin embargo, las estadísticas elaboradas por Moyano Gacitúa revelaron que estas nacionalidades no ocupaban en la Argentina el alto lugar que en la escala de la criminalidad tenían en Europa ${ }^{68}$. Por encima de ellos se hallaban los inmigrantes americanos (chilenos, uruguayos, brasileros y norteamericanos). Para explicar este fenómeno, aplicó la premisa de Lombroso que indicaba que "la inmigración mientras es más inestable es más delincuente". De acuerdo a esta fórmula, señaló que italianos y españoles llegaban al país con mayores intereses en ocuparse de manera permanente en las actividades productivas y comerciales. En contrapartida, los americanos eran más proclives a la inmigración "golondrina", es decir, registraban mayor tendencia al nomadismo, la alta movilidad y el escaso arraigo en el país, situación facilitada por la cercanía al lugar de origen ${ }^{69}$. Así, matizó el influjo de la raza en la relación entre inmigración y delincuencia y, en contrapartida, reconoció la importancia del nivel de estabilidad y movilidad ocupacional de los trabajadores extranjeros.

Por otra parte, advirtió que la concentración urbana de los inmigrantes, particularmente en Buenos Aires y Rosario, tendía a elevar sus niveles de criminalidad. El inmigrante permanecía en la ciudad, donde la gran oferta de mano de obra estimulaba la desocupación de una gran cantidad de recién llegados que se lanzaban a las calles en búsqueda de un sustento. A partir de allí, el camino quedaba abierto al desarrollo de un variopinto conjunto de actividades ilícitas, que incluía homicidios, lesiones, huelgas, estafas y hurtos ${ }^{70}$. Corroboró así lo demostrado por Joly para el caso de la ciudad francesa de Cette, donde los inmigrantes "faltos de trabajo seguro han vagado delinquiendo en todas las delincuencias"

De esta manera, Moyano Gacitúa puso el foco del análisis en la relación entre el delito y el mercado laboral. En efecto, la estructura productiva de la Argentina agroexportadora propició el trabajo estacional y la movilidad ocupacional. Las actividades de exportación requerían un elevado número de trabajadores durante la primavera y el verano, pero expulsaban mano de obra durante el invierno. En las ciudades, la construcción, la producción manufacturera y los servicios demandaron fuerza de trabajo de tipo ocasional; crearon empleos inestables que dependían de las condiciones generales de la economía, del gasto público o de decisiones políticas. Esto estimuló una gran movilidad ocupacional y geográfica entre los recién llegados, forzándolos a cambiar constantemente de trabajo a fin de mantener ingresos regulares durante todo el año. Gran número de trabajadores ocasionales, frustrados por el prolongado desempleo o por los cambios incesantes de

\footnotetext{
${ }^{68}$ Moyano Gacitúa, C., La delincuencia, Op. Cit., p. 331.

${ }^{69}$ Moyano Gacitúa, C., La delincuencia, Op. Cit., p. 330.

${ }^{70}$ Moyano Gacitúa, C., La delincuencia, Op. Cit., p. 71-72.

${ }^{71}$ Moyano Gacitúa, C., La delincuencia, Op. Cit., p. 325.
} 
ocupaciones, salarios y lugares de residencia, optaban por abandonar el mercado de trabajo e integrar el "mundo del delito"72.

Por último, la cuantificación le permitió observar la extensión social de la delincuencia. Arribó a esta conclusión a partir del examen estadístico del grado de criminalidad según distintos sectores profesionales. Para Moyano Gacitúa, la profesión ejercía una poderosa influencia en el modo de vida de los individuos, pues condicionaba sus gustos, sus relaciones sociales, su grado de moralidad y, por ende, sus tendencias criminales: "la profesión constituye un medio individual dentro del cual gira la actividad, levanta o baja el nivel del individuo e informa su personalidad social y humana"73. A partir de los datos cuantitativos extraídos de censos y archivos judiciales, distinguió diferentes categorías socio-profesionales y examinó la frecuencia y las tendencias que la delincuencia asumía en cada uno de los grupos.

Empleados, comerciantes y obreros industriales adquirían preponderancia en los índices delictivos, mientras que los trabajadores agropecuarios y los profesionales liberales ocupaban los niveles más bajos. Para explicar el elevado porcentaje de delincuencia que presentaban los empleados consideró tres factores: en primer lugar, que la mayoría de ellos se desempeñaba en el comercio, una de las actividades que acusaba mayor cantidad de delitos; en segunda instancia, que dentro del "gremio" de los empleados se sumaban también los de la administración pública, que agregaban a sus delitos aquellos relacionados con la política; por último, cierta tendencia a la holgazanería, el vicio y la imprevisión ${ }^{74}$.

La alta delincuencia del gremio de los empleados era seguida por la de los comerciantes. Los delitos relacionados con el comercio incluían el aumento de los precios, la adulteración del peso y la calidad de los productos, las falsificaciones de marcas y artículos y otras estafas, fraudes y engaños. Estos ilícitos eran considerados delitos contra la propiedad y, entre sus causas, se mencionaba la avaricia, el afán de lucro y la preocupación por lograr un enriquecimiento sin atender a la legalidad de las prácticas. A esto agregó el bajo nivel educativo de sus dependientes y la competencia desenfrenada que se desataba dentro del mismo gremio ${ }^{75}$.

En el tercer lugar de la escala de criminalidad ubicó a los obreros industriales. En este caso, describió algunos aspectos vinculados a las condiciones de vida y de trabajo de este

72 Salvatore, Ricardo, "Criminología positivista, reforma de prisiones y la cuestión social/obrera en Argentina” en Suriano, J. (comp.), La cuestión, Op. Cit., p. 144-153.

73 Moyano Gacitúa, C., La delincuencia, Op. Cit., p. 245.

${ }^{74}$ Moyano Gacitúa, C., La delincuencia, Op. Cit., p. 293-295.

${ }^{75}$ Según Oscar Terán, la creencia en que el comercio corrompe las buenas costumbres es constitutiva de la cultura occidental y ha sido denominada "el lamento de Platón, típico de la clase más baja del alma y de los estratos más despreciables de la comunidad". Terán, Oscar, Vida intelectual en el Buenos Aires fin-de-siglo (1880-1910). Derivas de la "cultura cientifica", Fondo de Cultura Económica, Buenos Aires, 2000, p. 52. 


\section{Revista Historia y Justicia}

sector que contribuían a explicar las razones y características de su delincuencia. Señaló que el estrecho contacto entre los obreros favorecía las rivalidades y riñas, y la mixtura de hombres y mujeres intensificaba los abusos y las violaciones. El alcoholismo y el bajo nivel educacional también eran factores que agravaban el peligro que la clase obrera representaba en materia de criminalidad. De la lectura del informe de Bialet Massé, sobre la situación de las clases trabajadoras en el interior del país, Moyano Gacitúa concluyó además que la baja remuneración, el maltrato patronal y la falta de asociaciones específicas para su defensa también podían ser factores criminógenos.

Ligeramente por encima del crimen del hombre de campo se ubicaba el delito de las profesiones liberales. Este fenómeno no era preocupante en términos cuantitativos, pero le resultaba significativo en la medida en que reflejaba las tendencias modernas que asumía la delincuencia, y porque daba cuenta de las transformaciones más globales experimentadas por la sociedad. Abogados, ingenieros, contadores, procuradores, médicos, escribanos, farmacéuticos y maestros ocupaban el cuarto nivel de criminalidad. Los hechos delictivos más comunes de los profesionales eran las estafas, los delitos políticos, las calumnias y las injurias.

Con esto, Moyano Gacitúa concluyó que el fenómeno de la delincuencia se extendía socialmente. El resultado no es menor si se considera que, en su obra de 1899, el autor no había dudado en asociar la criminalidad a las clases bajas de la sociedad ${ }^{76}$. La investigación empírica desarrollada seis años después le reveló que el comportamiento delictivo se encontraba disperso en todas las esferas de la vida y en todos los círculos de la sociedad: "desde la célula social hasta el más encumbrado conjunto de orden humano"77.

Para explicar esta situación, su trabajo vinculó al delito con los efectos perniciosos de la modernidad $^{78}$. En el trasfondo del proceso de modernización experimentado por la sociedad argentina del giro de siglo, Moyano Gacitúa advirtió las manifestaciones de una profunda crisis de decadencia espiritual y pérdida de valores de un pasado reciente. La modernidad multiplicaba y complejizaba las necesidades y los deseos. La lucha por la vida, la búsqueda del placer y la persecución de intereses personales componían una tendencia utilitarista que se tornaba predominante. El bienestar se procuraba de manera inmediata y el movimiento se hacía incesante, pues los hombres se sentían impulsados a avanzar hacia adelante, animados por el anhelo de encontrar "algo mejor". Las metas se vaciaban de contenido y los medios para alcanzarlas se volvían cada vez más egoístas. El individuo era movido por el solo propósito de experimentar el gozo, triunfar sobre otros u obtener una ganancia ${ }^{79}$.

\footnotetext{
${ }^{76}$ Moyano Gacitúa, C., Curso Ciencia Criminal, Op. Cit., p. 192.

77 Moyano Gacitúa, C., La delincuencia, Op. Cit., p. 345.

78 Galeano, D., "Civilización”, Op. Cit.

79 Moyano Gacitúa, C., La delincuencia, Op. Cit., p. 367.
} 
De acuerdo a la mirada de Moyano Gacitúa, los ideales del espíritu habían sido conmovidos por las pasiones del mercado. El sacrificio, la reflexión, la abnegación, el desinterés y el altruismo habían quedado postergados. Al final de esta frenética marcha, sólo quedaban los despojos de "todo lo que tuvo que consumir, todo lo que tuvo que devorar en su vértigo": la fortuna del pobre, la sangre del débil, el honor de la virgen, la vida del monarca. La fórmula de la vida moderna había trastocado y aniquilado los valores tradicionales ${ }^{80}$.

\section{A modo de cierre}

El pensamiento de Moyano Gacitúa resiste cualquier tipo de clasificación esquemática. Sus ideas penales no admiten ser calificadas como estrictamente clásicas, a pesar de haber adherido a muchas premisas asociadas a dicha corriente, sobre todo en lo que alude a la defensa del principio del libre albedrío. Tampoco es posible declararlo abiertamente positivista, pues cuestionó con firmeza las versiones más extremas que minimizaban el lugar de la voluntad humana. No obstante, a pesar de los "errores" que detectó en la escuela positivista, reconoció la importancia de su aporte metodológico para el desarrollo de una ciencia penal. Ello le resultó crucial para investigar los factores causales de la delincuencia en el país.

Interesado en construir un saber criminológico de acuerdo a la cultura científica de la época, Moyano Gacitúa llevó adelante un intensivo trabajo de recopilación de datos cuantitativos. En un momento de urbanización acelerada, de recepción de un gran flujo migratorio, de movilización obrera y de crecimiento de la criminalidad, la cuantificación se

\footnotetext{
80 Moyano Gacitúa no creía en la posibilidad de erradicar completamente la delincuencia, pero consideraba que podían implementarse políticas capaces de mejorar la situación. En consecuencia, su trabajo científico no excluyó los asuntos de gobierno de su horizonte de intereses. Según su visión, los hombres de Estado debían contener el avance del delito con el auxilio de los criminólogos, quienes estaban llamados a resolver el "enigma de la criminalidad" y sugerir a las autoridades los caminos a seguir. Parte importante de las medidas propuestas para el tratamiento de la delincuencia tenían un sentido preventivo. En este punto, adscribía a las enseñanzas de Enrico Ferri, para quien los medios preventivos funcionaban como "sustitutos de la pena", pues evitaban la ocurrencia del delito. No era necesario esperar a que los individuos cometieran una falta; podía intervenirse con antelación, previniendo el crimen mediante el mejoramiento de las condiciones de existencia humana. En La delincuencia argentina, Moyano Gacitúa insistió en la educación como vía prioritaria para la prevención del delito. En contraposición a la mera instrucción en saberes prácticos, la educación aludía aquí a la enseñanza de un conjunto de patrones de conducta, es decir, un modo de obrar, de comportarse y de conducirse en sociedad. Se trataba, en definitiva, de "enseñar al niño a ser bueno." Ello implicaba inculcar reglas de comportamiento contrarias al criterio utilitarista que regía la búsqueda del beneficio personal, sobre la base de la adquisición de bienes materiales y el despojo de otros hombres. Las escuelas estaban llamadas a mostrar al niño la diferencia entre lo bueno y lo malo, revelándole sus deberes y derechos, haciéndole conocer la relación entre sus actos y las leyes penales y estimulándolo a progresar por su propio esfuerzo, sin perjudicar a sus semejantes. Moyano Gacitúa, C., La delincuencia, Op. Cit., p. 215-224.
} 


\section{Revista Historia y Justicia}

presentaba como la base a partir de la cual observar la sociedad y ordenar una realidad caótica mediante principios racionales.

Estas operaciones metodológicas le permitieron constatar la existencia de una "cuestión penal argentina". Ésta se caracterizaba por el incremento de los índices de delincuencia, como así también por el cambio de forma del delito y su infiltración en todas las capas sociales. Afirmó que el problema de la delincuencia hundía sus raíces en el mundo social. Más específicamente, que era resultado de las transformaciones que la sociedad argentina había experimentado con la modernización (entre ellas, el desarrollo de las actividades productivas, la intensificación de los movimientos y las circulaciones, y las crecientes interacciones y fricciones sociales derivadas del aumento demográfico y la concentración urbana). Así, paradójicamente, la expansión del delito se presentaba como una derivación residual del avance de la civilización y del progreso humano.

Para Moyano Gacitúa, esto constataba que los actos delictivos evolucionaban conforme lo hacían las actividades humanas, porque eran un producto de la organización social y sus transformaciones. La frecuencia y las características del delito eran indisociables de la sociedad en la cual se desarrollaba y el acto expresaba en sí mismo las tendencias y contradicciones del orden social en su conjunto, en contextos históricamente definidos.

Estos argumentos fueron elaborados sobre la base de procedimientos y métodos de validación de la ciencia; por ende, permiten observar que su obra estuvo animada por una fuerte vocación empírica. Sin embargo, ello no significó el completo abandono de las interpretaciones y concepciones subjetivas de la sociedad. En efecto, asumía que el problema de la delincuencia estaba indisociablemente unido a los cambios sociales inaugurados por la modernización. Pero, más aún, la delincuencia era una expresión de la mutación de los valores, que la modernidad había desencadenado. Moyano Gacitúa se declaró enemigo del predominio de los criterios materialistas, convencido de que el mero afán de placeres, posesiones, éxito y lujos conducía a los hombres a una búsqueda egoísta, en la que olvidaban sus más elementales sentimientos de humanidad. Y si esta lectura evidenciaba la añoranza de un mundo pretérito que había sido conmovido, no abandonaba las pretensiones de crear un orden nuevo, capaz de imponerse en el magma de posibilidades abiertas por el cambio. Así, como en otras áreas vinculadas con la cuestión social, la producción de conocimiento sobre la criminalidad urbana combinó una serie de realidades e indicios objetivos con percepciones y subjetividades.

En conjunto, la obra particular de Cornelio Moyano Gacitúa entrega claves que contribuyen a enriquecer el conocimiento de los intelectuales que adhirieron a la criminología positivista en la Argentina de entre siglos. Su análisis revela que esta disciplina no sólo fue desarrollada por figuras conspicuas que hablaban en y desde Buenos Aires, sino también por hombres de ideas de las provincias, que participaron de ese colectivo y realizaron sus aportes 
particulares. La transferencia de los discursos del positivismo europeo hacia los espacios extra-céntricos estuvo lejos de implicar una simple reproducción mecánica de categorías y modelos conceptuales, pues cada recepción implicó un complejo proceso de apropiaciones selectivas y adaptaciones críticas. Así, descentrar la mirada de los intelectuales porteños y examinar la singularidad de algunas trayectorias del interior permite complejizar la visión sobre ese conjunto, y reconocer una mayor heterogeneidad y densidad en su seno.

\section{Fuentes}

\section{Inéditas}

Universidad Nacional de Córdoba, Archivo General e Histórico, Documentos, años 1890-1911.

Archivo de la Facultad de Derecho y Ciencias Sociales, Actas de Sesiones, años 1890-1905.

\section{Publicadas}

Cárcano, Ramón J., Universidad de Córdoba. Algunas palabras sobre su organización, Félix Lajouane, Buenos Aires, 1892.

Facultad de Derecho y Ciencias Sociales de la Universidad Nacional de Córdoba, Programa de Derecho Penal para el año 1890, La Minerva, Córdoba, 1890.

Gómez, Eusebio, Criminología argentina, Librería e Imprenta Europea, Buenos Aires, 1912.

Jiménez de Asúa, Luis, Tratado de Derecho Penal, tomo I, Editorial Losada, Buenos Aires, 1950.

Moyano Gacitúa, Cornelio,

-Curso de Ciencia Criminaly Derecho Penal Argentino, Félix Lajouane, Buenos Aires, 1899.

-La delincuencia argentina ante algunas cifras y teorías, Buena Vista, Córdoba, 2012.

-La Universidad en la época actual, La Patria, Córdoba, 1903.

-Notas de filosofía penal sobre el anarquismo, Imprenta La Patria, Córdoba, 1894.

Proyecto de Código Penal para la República Argentina, Tipografía de la Cárcel de Encausados, Buenos Aires, 1906.

Rivarola, Rodolfo, Derecho Penal Argentino, Librería Rivadavia, Buenos Aires, 1910.

Soler, Sebastián, Cornelio Moyano Gacitúa, Academia Nacional de Derecho y Ciencias Sociales, Córdoba, 1961.

Terán, Juan B., Estudios y Notas, tomo I, Universidad Nacional de Tucumán, Tucumán, 1980.

\section{Bibliografía}

Agüero, Ana Clarisa, "Comunidades, circuitos y lugares relativos en la cultura nacional. Caída y reparación de Córdoba entre dos generaciones
(1880-1920)" en Laguarda, Paula \& Flavia Fiorucci (eds.), Intelectuales, cultura y politica en espacios regionales de Argentina (siglo XX), Prohistoria, Rosario, 2012, p. 55-77 
ISSN 0719-4153 revista.historiayjusticia.org N8 - Santiago de Chile, abril 2017, p. 166-194
—.Trayectorias divergentes. Derecho, universidad y cultura en el giro de siglo cordobés", Miradas alternativas. Revista de ciencias sociales, Córdoba, n²4, 2008, p. 6-15.

Baratta, Alessandro, Criminología crítica y crítica del derecho penal: introducción a la sociología jurídico penal, Siglo XXI, Buenos Aires, 2004.

Blackwelder, Julia Kirk \& Lyman L. Johnson, "Estadística criminal acción policial en Buenos Aires, 1887-1914", Desarrollo Económico, Buenos Aires, vol. 24, n93, 1984, p. 109-121.

Buchbinder, Pablo, ¿Revolución en los claustros? La Reforma Universitaria de 1918, Editorial Sudamericana, Buenos Aires, 2008.

, "Controversias sobre la vida universitaria entre el antiguo régimen y la Reforma" en Saur, Daniel \& Alicia Servetto (coords.), Universidad Nacional de Córdoba. Cuatrocientos años de historia, tomo II, Universidad Nacional de Córdoba, Córdoba, 2013, p. 11-25.

Caimari, Lila, Apenas un delincuente: crimen, castigo y cultura en la Argentina, 1880-1955, Siglo XXI, Buenos Aires, 2004.

, Mientras la ciudad duerme. Pistoleros, policías y periodistas en Buenos Aires, 1920-1945, Siglo XXI, Buenos Aires, 2012.

Cesano, José Daniel \& Jorge Alberto Núñez, "La criminalidad en Buenos Aires de Miguel A. Lancelotti: Una aproximación contextual al autor y su obra" en Cesano, José Daniel \& José Alberto Núñez, Visiones de la criminología argentina (1903-1924). Una aproximación bistoriográfica, Editorial Brujas, Córdoba, 2014, p. 41-76.

Cesano, José Daniel, "Cornelio Moyano Gacitúa: su pensamiento en la tradición criminológica Argentina (1899-1905)", en Moyano Gacitúa, C., La delincuencia argentina ante algunas cifras y teorias, Buena Vista, Córdoba, 2012, p. 11-45.
— Élites, redes intelectuales y recepción en la cultura jurídico penal de Córdoba: 1900-1950, Ediciones del Copista, Córdoba, 2011.

Daniel, Claudia, "Medir la moral pública. La cuantificación policial del delito en Buenos Aires, 1880-1910", Estatística e Sociedade, Porto Alegre, n¹, 2011, p. 149-165.

Del Olmo, Rosa, América Latina y su criminología, Siglo XXI, México D. F., 1984.

Galeano, Diego, "Civilización y delito. Notas sobre cuatro criminólogos argentinos", Revista de Historia del Derecho, Buenos Aires, n45, 2013, p. 265-277.

Geli, Patricio, "Los anarquistas en el gabinete antropométrico. Anarquismo y criminología en la sociedad argentina del 900", Entrepasados, Buenos Aires, n², 1992, p. 7-24.

González Bollo, Hernán, "Francisco Latzina (1843-1922), funcionario estadístico del Estado argentino (1880-1916)", Estatística e Sociedade, Porto Alegre, n³, 2013, p. 110-121.

González, Marcela, "El medio, los actores y las ideas en la Universidad de Córdoba, 19001910”, Studia, Córdoba, n5, 1996, p. 175-224.

Imízcoz, José María, “Actores, redes, procesos: reflexiones para una historia más global”, Revista da Facultade de Letras. Historia, Porto Alegre, n5, 2004, p. 115-140.

Luciano, Milena, "Las ideas penitenciarias en el campo jurídico cordobés. 1885-1911", Anuario de la Escuela de Historia Virtual, Córdoba, $\mathrm{n}^{\circ} 4$, 2013, p. 75-92.

Melossi, Darío \& Sozzo, Máximo \& Richard Sparks (eds.), Travels of the Criminal Question. Cultural Embeddedness and Diffusion, Hart Publishing, Oxford, 2011.

Olaeta, Hernán, "Surgimiento de las estadísticas criminales en Argentina. La influencia de los discursos criminológicos en la producción y 
análisis de datos de la Ciudad de Buenos Aires (1885-1921)", Delito y Sociedad. Revista de Ciencias Sociales, Buenos Aires, vol. 2, n40, 2015, p. 31-62.

Ruibal, Beatriz Celina, Ideología del control social. Buenos Aires 1880-1920, CEAL, Buenos Aires, 1993.

"El control social y la policía de Buenos Aires 1880-1920", Boletin del Instituto de Historia Argentina y Americana "Dr. Emilio Ravignani", Buenos Aires, n², 1990, p. 75-90.

Salvatore, Ricardo, "Criminología positivista, reforma de prisiones y la cuestión social/obrera en Argentina" en Suriano, Juan (comp.), La cuestión social en Argentina, 1870-1943, La Colmena, Buenos Aires, 2000, p. 127-158.

"Criminology, prison reform and the Buenos Aires working class", Journal of Interdisciplinary History, Cambridge, vol. 23, $\mathrm{n}^{\circ} 2$, 1992, p. 279-299.

"Sobre el surgimiento del estado médico-legal en la Argentina (1890-1940)", Estudios Sociales, Santa Fe, n²0, 2001, p. 81-114.

"Usos científicos de La mala vida de Eusebio Gómez" en Salvatore, Ricardo \& Osvaldo Barreneche (eds.), El delito y el orden en perspectiva histórica, Prohistoria, Rosario, 2013, p. 99-120.
Sozzo, Máximo, “ 'Traduttore traditore'. Traducción, importación cultural e historia del presente de la criminología en América Latina", Cuadernos de Doctrina y Jurisprudencia Penal, Buenos Aires, vol. 7, n¹3, 2001, p. 353-431.

'Los exóticos del crimen'. Inmigración, delito y criminología positivista en la Argentina (1887-1914)", Delito y Sociedad. Revista de Ciencias Sociales, Buenos Aires, vol. 2, n³2, 2011, p. 19-51.

Suriano, Juan, "Introducción: una aproximación a la definición de la cuestión social en Argentina" en Suriano, Juan (comp.), La cuestión social en Argentina, 1870-1943, La Colmena, Buenos Aires, 2000, p. 1-29.

Taylor, Ian \& Walton, Paul \& Jock Young, La nueva criminología. Contribución a una teoría social de la conducta desviada, Amorrortu Editores, Buenos Aires, 1997.

Terán, Oscar, Vida intelectual en el Buenos Aires fin-de-siglo (1880-1910). Derivas de la "cultura cientifica", Fondo de Cultura Económica, Buenos Aires, 2000.

Zimmermann, Eduardo, Los liberales reformistas. La cuestión social en la Argentina 1890-1916, Editorial Sudamericana, Buenos Aires, 1995. 